PAPER

\title{
Evidence for distinct cognitive deficits after focal cerebellar lesions
}

\author{
B Gottwald, B Wilde, Z Mihajlovic, H M Mehdorn
}

J Neurol Neurosurg Psychiatry 2004;75:1524-1531. doi: 10.1136/jnnp.2003.018093

See end of article for authors' affiliations

....

Correspondence to: Dr B Gottwald, Zentrum für Integrative Psychiatrie ZIP,

Niemannsweg 147 ,

D-24105 Kiel, Germany;

b.gottwald@zip-kiel.de

Received 22 May 2003

In revised form

17 February 2004

Accepted

18 February 2004

Objectives: Anatomical evidence and lesion studies, as well as functional magnetic resonance imaging ( $\mathrm{fMRI}$ ) studies, indicate that the cerebellum contributes to higher cognitive functions. Cerebellar posterior lateral regions seem to be relevant for cognition, while vermal lesions seem to be associated with changes in affect. However, the results remain controversial. Deficits of patients are sometimes still attributed to motor impairment.

Methods: We present data from a detailed neuropsychological examination of 21 patients with cerebellar lesions due to tumour or haematoma, and 21 controls matched for age, sex, and years of education.

Results: Patients showed deficits in executive function, and in attentional processes such as working memory and divided attention. Further analysis revealed that patients with right-sided lesions were in general more impaired than those with left-sided lesions.

Conclusions: Those hypotheses that suggest that lesions of the right cerebellar hemisphere lead to verbal deficits, while those of the left lead to non-verbal deficits, have in part been confirmed. The generally greater impairment of those patients with a right-sided lesion has been interpreted as resulting from the connection of the right cerebellum to the left cerebral hemisphere, which is dominant for language functions and crucial for right hand movements. Motor impairment was correlated with less than half of the cognitive measures, with no stronger tendency for correlation with cognitive tests that require motor responses discernible. The results are discussed on the basis of an assumption that the cerebellum has a predicting and preparing function, indicating that cerebellar lesions lead to a "dysmetria of thought."

1: the last decade evidence has accumulated that suggests that the cerebellum is involved not only in motor but also in cognitive functions. This view is supported by the fact that the cerebellum contains more than half of all the neurones in the brain. ${ }^{1}$ The cerebellum is strongly interconnected with the contralateral cerebral hemispheres in both feedforward and feedback directions. Higher order cerebral areas, including the dorsolateral prefrontal cortex, as well as the parietal and superior temporal areas, project via the pons to the cerebellum. The feedback loop connects the deep cerebellar nuclei with cerebral areas, via the red nucleus and the thalamus. ${ }^{23}$ The rate of cerebellar afferents is, compared to the efferents, far higher, ${ }^{4}$ which suggests an integrative role for the cerebellum.

Positron emission tomography (PET) and functional magnetic resonance imaging (fMRI) studies have shown cerebellar activity in healthy control subjects in different cognitive tasks. Independent of motor involvement, different areas of the cerebellum were activated by non-spatial shifting attention tasks or selective attention tasks in two studies. ${ }^{56}$ Right cerebellar activation has been reported in verbal fluency paradigms..$^{7-9}$ The site of activation (right or left cerebellar hemisphere) seems to be contralateral to the activation of the frontal cortex, even under conditions of different language dominance. ${ }^{10}$ Greater cognitive demands in verbal fluency tasks seem to lead to more extensive cerebellar activation. ${ }^{11}{ }^{12}$

Further evidence for functions of the cerebellum, in addition to the motor, has come from examination of cerebellar abnormalities in psychopathological disorders such as schizophrenia, autism, or attention deficit hyperactivity disorder. ${ }^{13-16}$

Many authorities have found neuropsychological deficits in patients with a variety of cerebellar diseases, while others have reduced the deficits to motor disabilities. In the former group are Schmahmann and Sherman, ${ }^{17}$ who postulated a "cerebellar cognitive affective syndrome" which implies an impairment of executive functions, and disturbances in spatial cognition, language deficits, and personality changes. The deficits have been attributed to the disruption of neural circuits linking prefrontal, temporal, posterior parietal and limbic cortices with the cerebellum. Right cerebellar lesions should lead to verbal deficits because of the crossed pathways, whereas in left cerebellar lesions spatial deficits should be prominent. This hypothesis has been confirmed for children with cerebellar lesions arising from tumour resection. ${ }^{18} 19$ Other studies have shown deficits resulting from cerebellar lesions in the areas of verbal fluency, ${ }^{20}{ }^{21}$ error detection, ${ }^{22}$ planning, ${ }^{23}$ effortful memory, ${ }^{24}$ non-motor associative learning, ${ }^{25}$ spatial attention, ${ }^{26}$ and shifting attention. ${ }^{27}$ However, other researchers have failed to replicate these results $^{28}{ }^{29}$ or doubt the cognitive function of the cerebellum, instead explaining possible deficits by motor impairment or methodological problems. ${ }^{30}$ Ravizza and Ivry, ${ }^{31}$ for example, showed that lower motor demands reduced the deficits that cerebellar patients showed on an alternating attention task.

A convincing model for the possible function of the cerebellum in cognition has been presented by Courchesne and Allen. ${ }^{32}$ They see the cerebellum as a mechanism predicting the internal conditions for a particular motor or mental operation. It then sets the corresponding conditions in preparation, for example by altering cerebral blood flow levels or by enhancing neural responsiveness in different

Abbreviations: $\mathrm{FMRI}$, functional magnetic resonance imaging; MCST Modified Card Sorting Test; MWT-B, "Mehrfachwahl Wortschatztest"; PET, positron emission tomography; POMS, Profile of Mood States; TAP, "Testbatterie zur Aufmerksamkeitsprüfung"; TMT, Trail-Making-Test; UCT, universal cerebellar transform; WAIS-R, Wechsler Adult Intelligence Test-Revised; WMS-R, Wechsler Memory Scale Revised 
Table 1 Patient characteristics

\begin{tabular}{|c|c|c|c|c|c|c|c|}
\hline Patient & Sex & Age (years) & Years of education & Diagnosis & Lesion size $\left(\mathrm{cm}^{2}\right)$ & Lesion side & Point of assessment \\
\hline MJ & $\mathrm{F}$ & 50 & 13 & Metastasis & 7.5 & Left & Pre-op \\
\hline GJ & $F$ & 41 & 18 & Meningioma & 9 & Right & Pre-op \\
\hline HK & M & 67 & 11 & Metastasis & 20 & Right & Pre-op \\
\hline WD & $M$ & 57 & 13 & Metastasis & 4 & Left & Pre-op \\
\hline RR & $\mathrm{F}$ & 59 & 11 & Haemangioblastoma & 2.25 & Right & 27 months post-op \\
\hline$M B$ & $M$ & 37 & 12 & Angioma & 9 & Left & 26 months post-op \\
\hline $\mathrm{CH}$ & $\mathrm{F}$ & 40 & 9 & Angioma & 6 & Right & 18 months post-op \\
\hline$M B$ & $\mathrm{~F}$ & 49 & 18 & Meningioma & 22.5 & Right & Pre-op. \\
\hline PK & M & 61 & 12 & Haematoma & 15 & Right & 11 months post-op \\
\hline HS & M & 26 & 19 & Haemangioblastoma & 1.5 & Left & Pre-op \\
\hline FP & M & 63 & 10 & Haematoma & 7.5 & Left & Post-op \\
\hline ME & $\mathrm{F}$ & 54 & 10 & Meningioma & 25 & Left & Pre-op \\
\hline WJ & M & 65 & 13 & Metastasis & 24 & Right & Pre-op \\
\hline IG & $F$ & 66 & 11 & Meningioma & 27.5 & Right & Pre-op \\
\hline AS & M & 36 & 18 & Ganglioglioma & 49 & Right & Post-op \\
\hline RL & $M$ & 71 & 6 & Metastasis & 6 & Right & Pre-op \\
\hline $\mathrm{RH}$ & $\mathrm{F}$ & 48 & 12 & Meningioma & 12.25 & Left & Pre-op \\
\hline VT & $M$ & 45 & 13 & Haematoma & 3 & Right & Post-op \\
\hline GB & $\mathrm{F}$ & 62 & 13 & Metastasis & 13.5 & Left & Pre-op \\
\hline KS & $M$ & 63 & 16 & 2 metastases & 9,1 & Bilateral & Pre-op \\
\hline HM & $\mathrm{F}$ & 45 & 13 & Haematoma & 3 & Medial & Pre-op \\
\hline
\end{tabular}

areas. Sensory processing, as well as motor and mental performance, are smoothed and facilitated by these preparations. Therefore cerebellar damage will not eliminate the functions, but instead increase suboptimal variability in responses and conscious effort when performing motor or mental tasks. Cerebellar involvement in a wide range of functions has been observed in neuroimaging and lesion studies. Courchesne and Allen can account for this by ascribing a preparatory role to the cerebellum. Their theory "helps to explain the functional importance of massive input from cerebral cortical association areas, particularly prefrontal." ${ }^{\prime 32}$ They predict that the cerebellum must have a relatively global influence on a range of functions; deficits should be most pronounced in typical "frontal" functions and in tasks which involve a quick shift of attention. Because the functions will not be eliminated, but carried out suboptimally, the assumption seems to be in accord with the term "dysmetria of thought" postulated by Schmahmann and Sherman. ${ }^{17}$ Schmahmann ${ }^{33}$ proposes that the cerebellum regulates the appropriateness of cognitive processes in terms of speed, capacity, and consistency in the same way as it does the accuracy of movements. "Following a focal cerebellar lesion, the universal cerebellar transform (UCT) that modulates the function subserved by the specific lesioned cerebellar lesion is lost, and the resulting behavior is degraded, in a characteristic and unique manner. When the UCT is lost there is a resulting universal cerebellar impairment, or dysmetria." ${ }^{\prime 33}$

In summary, the results of studies dealing with neuropsychological deficits in patients with cerebellar lesions are still controversial. In many studies the samples consisted of patients with a variety of cerebellar diseases, and in the patients with degenerative cerebellar disease it seems questionable if the cerebellar lesions are the only reason for the deficits. Other studies lack control samples.

In order to contribute to the research on this issue we planned a study with patients with focal cerebellar lesions. The main goal of this study is to prove whether an undamaged cerebellum is a basic requirement for the optimal functioning of higher cognitive processes. A further question will be to see if the profile of deficits depends on the site of the lesion. According to Riva and Giorgi ${ }^{18}$ lateralised cerebellar lesions should lead to those deficits which are typical for contralateral lesions of the cerebrum. According to Courchesne and Allen $^{32}$ functions should not be eliminated but reduced. This reduction should be stronger in complex tasks than in simple ones.

We present here the results of the neuropsychological evaluation of patients with focal cerebellar lesions arising from tumour or haematoma who were hospitalised in our institute between 2000 and 2002. They are compared to a control group.

\section{METHODS}

\section{Subject selection}

Between 2000 and 2002 patients with focal cerebellar lesions were assessed by means of a neuropsychological test battery. Patients were excluded from detailed study for the following reasons: age under 18 or over 75; possession of other areas of lesion involving non-cerebellar cortical or subcortical regions, such as infarction or brain tumour; head trauma; history of drug or alcohol abuse; pre-existent psychiatric diagnoses. Patients were also excluded if their neurological status did not allow reliable neuropsychological testing.

Each patient underwent a comprehensive neurological examination, as well as MRI or CCT. Patients gave written consent to participate in this study.

\section{Patient characteristics}

A total of 21 patients were studied (11 male, 10 female: table 1). The age range of the group was 26-71 years (median: 55.5). Three patients were left-handed but they were all used to writing with the right hand. In five patients the vermis was affected. The deep cerebellar nuclei were involved in 15 patients, either by haematoma, tumour, or oedema. Lesion size was measured in $\mathrm{cm}^{2}$ in preoperative MRI. It is defined by the largest and second largest tumour extension in two different dimensions out of the horizontal, sagittal, and coronal dimensions. In case of acute onset of the disease (haematomas) it was not possible to see all patients before surgery and therefore to avoid possible direct surgical effects. In a few other cases organisational reasons did not allow pre-operative neuropsychological testing.

Fourteen patients presented a gait ataxia; cerebellar symptoms such as motor disturbances or dysarthria seemed only very mild if existing at all. The neurological examination did not include specific tests of oculomotor function, for example dysmetric saccades or abnormal pursuit, as have been described in cerebellar patients. ${ }^{34}$ However, every patient was asked about changes in vision and only two 
patients (HK, AS) reported having double vision. They were asked to keep one eye closed with an eye patch while performing the tests, and one of them (HK) did not perform the tasks presented on a computer. No patient demonstrated an aphasic syndrome or a hemispatial neglect. Preoperative MRI showed a slight brainstem compression in nine cases, and in seven cases a slight hydrocephalus.

The control sample consisted of 21 healthy controls matched for age, gender, and years of education. The age range of the control group was 27-75 years (median: 57). Two of the controls were left handed, but one of them was used to writing with the right hand. Like the patients, the controls gave written consent for participation in this study.

\section{Neuropsychological assessment}

Patients and controls received a detailed neuropsychological testing. The tests were administered in two sessions of approximately $1 \frac{1}{2}$ hours each. As most patients were studied preoperatively, and as an addition to the clinic routine, it was, for organisational reasons, not possible to administer all tests to all patients. Patients were also told that it was always possible to make a break, or even stop the testing, if it became too exhausting.

The following functions were tested:

- Estimation of premorbid intelligence: "Mehrfachwahl Wortschatztest," MWT-B. ${ }^{35}$

- Memory: Wechsler Memory Scale Revised, WMS-R ${ }^{36}$ (German version ${ }^{37}$ ).

- Executive functions: semantic (supermarket, animals, hobbies) and phonematic (L,B,S) verbal fluency (following $\operatorname{COWAT}^{38}$ ), figural fluency (Five Point Test ${ }^{39}{ }^{40}$ ), motor flexibility (Hand Movements, K-ABC, ${ }^{41}$ German version ${ }^{42}$ : following $\left.\operatorname{Luria}^{43}\right)$, Modified Card Sorting Test, MCST, ${ }^{44}$ Stroop-Test ${ }^{45}\left(\right.$ German version $\left.^{46}\right)$, Similarities, Wechsler Adult Intelligence Test-Revised, WAIS-R ${ }^{47}$ (German ver$\left.\operatorname{sion}^{48}\right)$.

- Visuo-spatial functions: Rey-Osterrieth Complex Figure Test, ${ }^{40}{ }^{49}$ Block Design, WAIS-R. ${ }^{47}$

- Attention: "Testbatterie zur Aufmerksamkeitsprüfung," TAP: Selective Attention, Divided Attention, Working Memory, ${ }^{50}$ Trail-Making-Test, TMT. ${ }^{40}{ }^{51}$

- Motor functions: Purdue Pegboard Test. ${ }^{52}$

- Affective state: Profile of Mood States, POMS. ${ }^{53}$

All of the tests were administered in their German version. Two original German tests have been used: MWT-B is a test to estimate premorbid intelligence; TAP is a commonly used German computerised attention test battery, including 12 subtests. Three of the subtests have been administered to the subjects in this study. Selective Attention (Go/NoGo) demands recognising two out of five similar patterns presented on the computer in a random order. The working memory task is based on the "two-back" principle, digits being randomly presented on the screen. In Divided Attention visual and acoustic stimuli are presented at the same time, demanding either a very quick shift of attention between the two modalities or parallel attention to both at the same time. In all three attention tasks subjects were instructed to respond to the targets by pressing the response key as quickly as possible. False alarms and misses as well as reaction time were recorded.

\section{Statistics}

The Mann-Whitney U test, a non-parametric test for two independent samples, was used to evaluate statistical significance. A non-parametric statistic test was chosen because Levenès Test for equality of variances revealed that equality of variances between the groups could not be assumed in all tests.

On the assumption that the cerebellar patients would be impaired the test was calculated one-sided. Standard norms are published for most of the tests; where this was the case we used percentiles or indices based on these norms for the statistical comparisons. If no norms were available we used raw scores for the comparison to the matched control group.

\section{RESULTS}

The results of all neuropsychological tests are shown in table 2 .

\section{Premorbid intelligence}

Since patients and controls were matched for age and years of education there should not be a difference in premorbid intelligence. As expected no significant group difference was found.

\section{Memory}

In the WMS-R patients showed a significant impairment in general memory, in delayed recall, and in visual memory, but not in verbal memory (table 3). Looking at the different subtests of the WMS-R, "Logical Memory" and "Visual Reproduction" showed significant differences. Neither "Verbal" nor "Visual Paired Associates" exhibited significant group differences. "Digit Span" and "Visual Memory Span" are also part of the WMS-R; they are considered as measures of attentional capacity or very short term memory. Neither subtests revealed any significant group differences.

\section{Executive functions}

Patients showed deficits in different aspects of executive functions. Semantic and phonematic fluency were clearly impaired since patients named less words than the controls. The number of drawings in the Five Point Test was also significantly smaller in the group of patients, but no group difference was seen concerning the percentage of perseveration. Patients were also impaired in the tests Similarities and Hand Movements. The Stroop Test has revealed group differences in the first two parts measuring verbal speed abilities, and in the third part which is also speed dependent. Regarding the difference between Parts II and III, which is crucial for response inhibition and selective attention, no group difference was discernible. There was no difference in the number of categories that patients and controls completed in the MCST.

\section{Visual construction}

The complex figure test showed no group differences in any of the three conditions (copy, recall, planning). In Block Design the patients were clearly impaired.

\section{Attention}

Very clear impairments were seen in the attention tasks on the computer. In all three tasks patients showed a larger variability in reaction time than controls. In the divided attention task patients missed significantly more target stimuli than the control group. Pronounced deficits were also seen in all parameters of the working memory task. Except for the greater variability in the reaction time of the patients that has already been described, no group differences have been detected in Go/NoGo. (No norms are available for false alarms in Divided Attention, nor for misses in $\mathrm{Go} / \mathrm{NoGo}$, and therefore those two test parameters are not described here.)

The TMT revealed significant group differences, patients were slower than controls in both parts. The difference between both parts also proved to be significant. 
Table 2 Results of the neuropsychological assessment for patients and controls

\begin{tabular}{|c|c|c|c|c|c|c|c|}
\hline \multirow[b]{2}{*}{ Function and test } & \multicolumn{3}{|c|}{ Patients } & \multicolumn{3}{|c|}{ Controls } & \multirow[b]{2}{*}{$\mathbf{p}$} \\
\hline & $\mathbf{n}$ & $M$ & SD & $\mathbf{n}$ & M & SD & \\
\hline \multicolumn{8}{|l|}{ Premorbid intelligence } \\
\hline MWT-B* & 21 & 71.10 & 27.79 & 21 & 82.93 & 17.32 & n.s. \\
\hline \multicolumn{8}{|l|}{ Memory } \\
\hline \multicolumn{8}{|l|}{ WMS-R } \\
\hline Verbal Memory§ & 18 & 98.78 & 25.26 & 21 & 111.38 & 14.85 & n.s. \\
\hline Visual Memory§ & 15 & 92.80 & 20.67 & 21 & 109.95 & 12.25 & 0.002 \\
\hline General Memory§ & 15 & 97.53 & 25.69 & 21 & 112.90 & 15.30 & 0.036 \\
\hline Delayed Recall§ & 15 & 94.93 & 22.55 & 21 & 109.71 & 13.48 & 0.018 \\
\hline \multicolumn{8}{|l|}{ Executive functions } \\
\hline \multicolumn{8}{|l|}{ Verbal fluency } \\
\hline Semantic fluency† & 19 & 49.00 & 11.13 & 20 & 66.35 & 16.72 & 0.001 \\
\hline Phonematic fluency† & 19 & 35.32 & 12.88 & 20 & 52.70 & 13.36 & 0.000 \\
\hline \multicolumn{8}{|l|}{ Five Point Test } \\
\hline Number of drawings $†$ & 20 & 24.30 & 12.05 & 21 & 31.43 & 8.39 & 0.014 \\
\hline Percent of perseveration & 20 & 9.31 & 9.36 & 21 & 7.49 & 5.54 & n.s. \\
\hline Hand movements $\dagger$ & 18 & 13.17 & 4.11 & 21 & 16.81 & 2.89 & 0.001 \\
\hline MCST categories† & 19 & 5.95 & 0.23 & 20 & 6.00 & 0.00 & n.s. \\
\hline \multicolumn{8}{|l|}{ Stroop Test } \\
\hline Color Word Reading (I)† & 18 & 36.61 & 10.56 & 20 & 29.95 & 6.30 & 0.017 \\
\hline Color Naming (II) $\dagger$ & 18 & 54.33 & 11.27 & 20 & 47.15 & 9.11 & 0.008 \\
\hline Interference (III) $\dagger$ & 18 & 104.83 & 51.20 & 20 & 87.45 & 28.65 & 0.049 \\
\hline Part III-Part II† & 18 & 50.50 & 45.84 & 20 & 40.30 & 21.47 & n.s. \\
\hline Similarities $\ddagger$ & 18 & 9.83 & 3.52 & 21 & 12.86 & 2.13 & 0.002 \\
\hline \multicolumn{8}{|l|}{ Visuo-constructive functions } \\
\hline \multicolumn{8}{|l|}{ Rey-Osterrieth Figure } \\
\hline Copy† & 19 & 31.79 & 3.29 & 21 & 33.40 & 2.23 & n.s. \\
\hline Recall $†$ & 19 & 14.39 & 5.97 & 21 & 17.31 & 7.39 & n.s. \\
\hline Planning† & 19 & 28.16 & 3.10 & 21 & 29.38 & 2.04 & n.s. \\
\hline Block Design $\ddagger$ & 17 & 9.53 & 3.04 & 21 & 11.43 & 2.98 & 0.003 \\
\hline \multicolumn{8}{|l|}{ Attention } \\
\hline \multicolumn{8}{|l|}{ Divided Attention } \\
\hline SD of reaction time* & 18 & 36.33 & 27.30 & 20 & 61.65 & 25.42 & 0.050 \\
\hline Md of reaction time* & 18 & 26.94 & 26.75 & 20 & 35.70 & 26.23 & n.s. \\
\hline Misses* & 18 & 23.72 & 21.40 & 20 & 52.35 & 21.60 & 0.000 \\
\hline Working Memory & & & & & & & \\
\hline SD of reaction time* & 17 & 34.06 & 28.47 & 20 & 50.55 & 32.79 & 0.005 \\
\hline Md of reaction time* & 17 & 28.65 & 27.45 & 20 & 49.75 & 33.14 & 0.026 \\
\hline Misses* & 17 & 24.29 & 23.23 & 20 & 34.10 & 21.85 & 0.042 \\
\hline False Alarms* & 17 & 34.88 & 30.26 & 20 & 53.95 & 28.93 & 0.019 \\
\hline Go/NoGo & & & & & & & \\
\hline SD of reaction time* & 18 & 30.89 & 32.47 & 20 & 50.85 & 33.80 & 0.046 \\
\hline Md of reaction time* & 18 & 37.55 & 35.03 & 20 & 48.60 & 35.40 & n.s. \\
\hline False Alarms* & 18 & 35.56 & 20.27 & 20 & 38.10 & 18.08 & n.s. \\
\hline Trail Making Test & & & & & & & \\
\hline Part $A^{*}$ & 20 & 43.77 & 25.33 & 21 & 67.98 & 21.49 & 0.001 \\
\hline Part $B^{*}$ & 20 & 49.32 & 25.60 & 21 & 72.55 & 20.60 & 0.001 \\
\hline Part B-Part A* & 20 & 46.62 & 30.50 & 21 & 69.05 & 26.46 & 0.012 \\
\hline Motor functions & & & & & & & \\
\hline Purdue Pegboard & & & & & & & \\
\hline Right hand $†$ & 19 & 11.37 & 3.20 & 21 & 13.57 & 1.72 & 0.017 \\
\hline Left hand† & 18 & 11.28 & 3.80 & 21 & 13.10 & 2.23 & n.s. \\
\hline Both hands† & 18 & 8.33 & 3.14 & 21 & 10.86 & 1.74 & 0.005 \\
\hline Affective state & & & & & & & \\
\hline POMS & & & & & & & \\
\hline Dejection† & 19 & 24.05 & 18.21 & 21 & 6.24 & 7.73 & 0.000 \\
\hline Tiredness† & 19 & 16.74 & 7.84 & 21 & 10.33 & 6.30 & 0.004 \\
\hline Initiative† & 19 & 15.37 & 7.11 & 21 & 25.24 & 7.25 & 0.000 \\
\hline Discontent† & 19 & 5.42 & 8.89 & 21 & 3.38 & 5.90 & n.s. \\
\hline
\end{tabular}

\section{Motor functions}

As expected, the patients proved to be impaired in motor function. When carried out only with the right hand, or with both hands at the same time, the Purdue Pegboard Test revealed a significant group difference. No difference was detected when only the left hand was used.

To check if the cognitive deficits depend on motor deficits, a non-parametric correlation (Spearman) was run between several cognitive tasks and the Purdue Pegboard Test with both hands at the same time. It is well known that a correlation analysis over several tests and in a rather small sample is not a very meaningful test because of the lack of power. However this analysis (without a corrected alpha) is meant to be looked at only descriptively to see if there is any pattern revealing influences of motor impairment. Table 4 shows that there is no stronger tendency for correlation with those tests that require motor responses. A general motor impact on the cognitive performance did not exist therefore.

\section{Affective state}

In a questionnaire the patients described themselves as significantly more dejected and tired, and also reduced in initiative, compared to the controls. No difference was found in the described discontent. 
Table 3 Results of the subtests of the WMS-R for patients and controls

\begin{tabular}{|c|c|c|c|c|c|c|c|}
\hline \multirow[b]{2}{*}{ Test } & \multicolumn{3}{|c|}{ Patients } & \multicolumn{3}{|c|}{ Controls } & \multirow[b]{2}{*}{$p$} \\
\hline & $n$ & Mean & SD & $n$ & Mean & SD & \\
\hline Figural Memory† & 18 & 6.78 & 1.48 & 21 & 7.57 & 1.54 & n.s. \\
\hline Logical Memory I* & 19 & 46.21 & 34.97 & 21 & 66.81 & 30.06 & 0.023 \\
\hline Logical Memory $\|^{*}$ & 19 & 50.21 & 34.82 & 21 & 70.76 & 25.64 & 0.028 \\
\hline Visual Reproduction I* & 15 & 30.60 & 28.41 & 21 & 61.43 & 26.77 & 0.001 \\
\hline Visual Reproduction II* & 15 & 29.40 & 24.92 & 21 & 56.00 & 32.33 & 0.006 \\
\hline Verbal Paired Associates I† & 18 & 19.61 & 4.96 & 21 & 21.57 & 1.72 & n.s. \\
\hline Verbal Paired Associates II $†$ & 18 & 7.11 & 1.37 & 21 & 7.76 & 0.44 & n.s. \\
\hline Visual Paired Associates It & 16 & 12.88 & 4.57 & 21 & 15.52 & 2.96 & n.s. \\
\hline Visual Paired Associates II† & 16 & 4.44 & 2.06 & 21 & 5.57 & 0.81 & n.s. \\
\hline Digit Span forwards* & 17 & 57.18 & 24.90 & 21 & 60.33 & 33.34 & n.s. \\
\hline Digit Span backwards* & 17 & 40.29 & 24.86 & 21 & 55.00 & 33.61 & n.s. \\
\hline Vis. Memory Span forwards $\dagger$ & 15 & 45.33 & 33.38 & 20 & 47.50 & 29.43 & n.s. \\
\hline Vis. Memory Span backwards† & 15 & 40.33 & 29.83 & 20 & 42.75 & 28.73 & n.s. \\
\hline
\end{tabular}

A Spearman correlation was run for the motor influences, to see if the significantly different measures of affect were correlated with cognitive performance to rule out a general impact of mood. The test was run with the measures Dejectedness, Tiredness, and Initiative, and the tests Similarities, Block Design, Verbal Memory, Visual Memory, Logical Memory I, Visual Reproduction I, Rey-Osterrieth Figure Copy, verbal fluency, TMT A and B, Hand Movements, and number of drawings and percentage of perseveration in the Five Point Test. Again these correlations without a corrected alpha are only meant to be looked at descriptively. Dejectedness had a significantly negative correlation with five out of the 11 tests: Similarities, verbal fluency, TMT A and B, and Hand Movements. Tiredness was only correlated negatively with Similarities and Logical Memory I. Initiative was correlated with verbal fluency, TMT B, misses in Divided Attention, and percentage of perseveration in the Five Point Test. In summary, it can be said that a general impact of mood did not exist (only 11 out of 69 correlations proved to be significant). Some of the performance in executive function was correlated with dejectedness and initiative, however, other tasks requiring effortful attention, such as Logical Memory I and Visual Reproduction I, were not correlated to these mood states. Therefore the range of cognitive deficits seen in our patients can not be explained by changes of affect.

\section{Deficits in patients seen prior to surgery}

To make sure that the deficits are truly due to the cerebellar lesions and not only to unspecific surgical effects, we checked

Table 4 Tests dependent on their correlation with motor function measured by Purdue Pegboard with both hands

\begin{tabular}{ll}
\hline $\begin{array}{l}\text { Significant correlation with } \\
\text { Purdue Pegboard }\end{array}$ & $\begin{array}{l}\text { No correlation with } \\
\text { Purdue Pegboard }\end{array}$ \\
\hline $\begin{array}{ll}\text { Logical Memory I } \\
\text { Visual Reproduction I }\end{array}$ & $\begin{array}{l}\text { Verbal memory } \\
\text { Verbal fluency }\end{array}$ \\
$\begin{array}{l}\text { Visual memory } \\
\text { Band Movements }\end{array}$ & Standard deviations of reaction \\
Number of drawings & time in: \\
(Five Point Test) & Go/NoGo \\
Percentage of perseveration & Divided Attention \\
(Five Point Test) & Working Memory \\
Similarities & Go/NoGo \\
Rey-Osterrieth figure copy & Divided Attention \\
Misses of Divided Attention & False alarms (Working Memory) \\
$\begin{array}{l}\text { Median of reaction time } \\
\text { (Working Memory) }\end{array}$ & Misses (Go/NoGo) \\
False alarms (Working Memory) & TMT (Part A and Part B) \\
\hline
\end{tabular}

the results from those patients who were seen before surgery. The results were very similar to those from the whole group. The only differences existed in General Memory and Delayed Recall, in the misses in Working Memory, in the standard deviation of reaction time in Go/NoGo, and in the performance with the right hand in Purdue Pegboard. Those were the only results that changed from being significantly different compared to the control group to having no significant difference. All other results remained the same.

\section{Deficits in patients with either a right- or left-sided lesion}

To see if there was a different pattern of deficits in right-sided as against left-sided lesions, we compared each group to their specific control group again. This was done by using the Mann-Whitney-U Test. The right-sided lesion group included 11 patients, the left-sided lesion group eight patients.

The patient subgroup with right-sided lesions showed deficits in almost all the tests that had proved to be significant in the wider group. Except for median reaction time in Working Memory, and standard deviation of reaction time in Go/NoGo, the same tests reached significance (table 5). However, patients with left-sided lesions showed only very few significant differences compared to their control group. Unlike patients with right-sided lesions, and unlike all patients as a group, patients with left-sided lesions proved to be impaired in the planning of the Rey-Osterrieth Figure. Further significant differences existed in Visual Memory, in misses in the divided attention task, in Dejection, and in Initiative.

Comparing the patients with a right-sided lesion to those with a left-sided lesion, no group difference existed for the diagnosis (descriptively) or the lesion size (Mann-Whitney U-Test, one-sided, assuming that the lesions on the right side might have been larger: $p=0.22$ ). In addition, no descriptive group difference was discernible for the other clinical variables (table 6).

\section{DISCUSSION}

This study describes the cognitive deficits observed in patients with cerebellar tumours or haematomas compared to a control group. Deficits have been detected by the use of a detailed neuropsychological test battery.

Comparing all the patients, regardless of the lesion site, to the matched control group, many functions proved to be impaired in the patient group. In the area of memory the WMS-R indices of General Memory and Delayed Recall were impaired, as well as Visual Memory. Looking at the different subtests of the WMS-R, there seems to be a difference depending on the amount of effort demanded by the tasks. 
Table 5 Results separated for patients with right- $(n=12)$ and left-sided lesions $(n=7)$ in comparison to their matched control group

\begin{tabular}{|c|c|c|}
\hline Function and test & $\begin{array}{l}\text { Right-sided lesion } \\
\text { (p) }\end{array}$ & $\begin{array}{l}\text { Left-sided lesion } \\
\text { (p) }\end{array}$ \\
\hline \multicolumn{3}{|l|}{ Pre-morbid intelligence } \\
\hline MWT-B* & n.s. & n.s. \\
\hline \multicolumn{3}{|l|}{ Memory } \\
\hline \multicolumn{3}{|l|}{ WMS-R } \\
\hline Verbal Memory§ & 0.030 & n.s. \\
\hline Visual Memory§ & 0.013 & 0.040 \\
\hline General Memory§ & 0.020 & n.s. \\
\hline Delayed Recalls & 0.045 & n.s. \\
\hline \multicolumn{3}{|l|}{ Executive functions } \\
\hline \multicolumn{3}{|l|}{ Verbal fluency } \\
\hline Semantic fluency $†$ & 0.000 & n.s. \\
\hline Phonematic fluency† & 0.002 & n.s. \\
\hline \multicolumn{3}{|l|}{ Five Point Test } \\
\hline Number of drawings $\dagger$ & 0.014 & n.s. \\
\hline Percent of perseveration & n.s. & n.s. \\
\hline Hand movements $†$ & 0.001 & n.s. \\
\hline MCST categories $†$ & n.s. & n.s. \\
\hline \multicolumn{3}{|l|}{ Stroop test } \\
\hline Color Word Reading (I)† & 0.002 & n.s. \\
\hline Color Naming (III)† & 0.002 & n.s. \\
\hline Interference(III) $\dagger$ & 0.036 & n.s. \\
\hline Part III-II† & n.s. & n.s. \\
\hline Similarities $\ddagger$ & 0.006 & n.s. \\
\hline \multicolumn{3}{|l|}{ Visuo-spatial functions } \\
\hline \multicolumn{3}{|l|}{ Rey-Osterrieth Figure } \\
\hline Copyt & n.s. & n.s. \\
\hline Recall $\dagger$ & n.s. & n.s. \\
\hline Planning† & n.s. & 0.019 \\
\hline Block Design $\ddagger$ & 0.003 & n.s. \\
\hline \multicolumn{3}{|l|}{ Attention } \\
\hline \multicolumn{3}{|l|}{ Divided Attention } \\
\hline $\mathrm{SD}$ of reaction time* & 0.018 & n.s. \\
\hline Md of reaction time* ${ }^{*}$ & n.s. & n.s. \\
\hline Misses* ${ }^{*}$ & 0.002 & 0.014 \\
\hline \multicolumn{3}{|l|}{ Working Memory } \\
\hline SD of reaction time* & 0.006 & n.s. \\
\hline Md of reaction time* & n.s. & n.s. \\
\hline Misses* $^{*}$ & 0.012 & n.s. \\
\hline False Alarms* & 0.005 & n.s. \\
\hline \multicolumn{3}{|l|}{ Go/NoGo } \\
\hline SD of reaction time* & n.s. & n.s. \\
\hline Md of reaction time* ${ }^{*}$ & n.s. & n.s. \\
\hline False Alarms* & n.s. & n.s. \\
\hline \multicolumn{3}{|l|}{ Trail Making Test } \\
\hline Part $A^{*}$ & 0.001 & n.s. \\
\hline Part $B^{*}$ & 0.004 & n.s. \\
\hline Part B-Part A* & 0.023 & n.s. \\
\hline \multicolumn{3}{|l|}{ Motor functions } \\
\hline \multicolumn{3}{|l|}{ Purdue Pegboard } \\
\hline Right handt & 0.036 & n.s. \\
\hline Left handt & n.s. & n.s. \\
\hline Both hands $†$ & 0.010 & n.s. \\
\hline \multicolumn{3}{|l|}{ Affective state } \\
\hline \multicolumn{3}{|l|}{ POMS } \\
\hline Dejection $†$ & 0.005 & 0.010 \\
\hline Tiredness $†$ & 0.025 & n.s. \\
\hline Initiative† & 0.006 & 0.010 \\
\hline Discontentt & n.s. & n.s. \\
\hline $\begin{array}{l}p \text {, significance after one-side } \\
\text { n.s., not significant. } \\
{ }^{*} p \text {, percentile; } t r \text {, raw score } \\
\text { index: mean }=100, S D=15 .\end{array}$ & Mann-Whitney U-tes & $\begin{array}{l}\text {; Md, median; } \\
=10, S D=3 ; \S i\end{array}$ \\
\hline
\end{tabular}

Patients were severely impaired in Logical Memory and Visual Reproduction. Both tests are "free-recall-tests," and can therefore be described as memory tests demanding more effort, and also more strategy, than the structured Paired Associates Tests (which were not significantly impaired). The results reported by Appollonio et $a^{24}$ indicate that patients with cerebellar degeneration are impaired in effortful memory, but not in implicit and automatic memory processes. They interpreted this impairment as secondary to deficits in executive functions. Other authorities did not find
Table 6 Patient characteristics separated for right- and left-sided lesions

\begin{tabular}{|c|c|c|}
\hline Patient characteristics & $\begin{array}{l}\text { Cases with right- } \\
\text { sided cerebellar } \\
\text { lesion }\end{array}$ & $\begin{array}{l}\text { Cases with left- } \\
\text { sided cerebellar } \\
\text { lesion }\end{array}$ \\
\hline Number & 11 & 8 \\
\hline Mild hydrocephalus & 4 & 2 \\
\hline Mild brainstem compression & 5 & 3 \\
\hline $\begin{array}{l}\text { Lesion involves mostly the } \\
\text { anterior cerebellum }\end{array}$ & 0 & 1 \\
\hline $\begin{array}{l}\text { Lesion involves mostly the } \\
\text { posterior cerebellum }\end{array}$ & 3 & 1 \\
\hline $\begin{array}{l}\text { Equal involvement of anterior } \\
\text { and posterior parts }\end{array}$ & 8 & 6 \\
\hline $\begin{array}{l}\text { Involvement of the deep } \\
\text { cerebellar nuclei }\end{array}$ & 7 & 7 \\
\hline
\end{tabular}

any memory impairment in patients with cerebellar lesions. ${ }^{54}$ However, we do not think that cerebellar lesions lead to memory impairments per se, but that in our sample those deficits were secondary to the impairment in executive function.

Most of the tests measuring executive functions revealed a significant impairment in the patient group. The number of items produced in the fluency tasks proved to be extremely reduced. Deficits in fluency after cerebellar lesions have consistently been reported by a number of authorities, ${ }^{17} 18202124$ with a central emphasis on verbal fluency. The important thing about this is that results in verbal fluency have been shown to be independent of dysarthria. ${ }^{17} 2024$ In our sample the fluency seems to have been impaired independently of the modality.

Surprisingly, except for a significant impairment in Block Design, no deficits have been revealed in visual construction. When considering copy and recall of the Rey-Osterrieth Figure the results differ from those of Schmahmann and Sherman. ${ }^{17}$ We do not have an explanation for this difference, but the patient's s ability to make a proper copy of the figure suggests a relatively normal visual perception that would also be significant for many other visual tests.

The attentional deficits show once again that the deficits cannot be only due to motor disturbances. If motor impairments were present, then they should have been seen in all three tasks, and would have manifested themselves in slowed reaction times. This was not the case. By contrast, the main differences were seen in the qualitative aspects of working memory and divided attention (for more details see Gottwald $e t \mathrm{al}^{55}$ ). Higher attentional functions such as divided attention proved to be clearly impaired, whereas the rather basic attentional function measured by Go/NoGo did not reveal any group differences. Therefore a general influence on other test performances does not seem likely.

A correlation with the Purdue Pegboard Test was run as a control for discerning whether there was any motor influence on the tasks. The resulting pattern was rather surprising. While some of the obviously motor related tests, like the TMT or Block Design, did not correlate with the Purdue Pegboard, some other non-speed tests, like Logical Memory or Similarities, did. Regarding the different functions, all the fluency tests, and even almost all of the tests for executive function, were correlated with motor function, whereas most of the attentional parameters were not.

Naturally we do not deny that there are motor impairments in patients with cerebellar lesions, but we do not think that all deficits can be attributed to the motor disabilities. It seems more likely that lesions of the cerebellum lead to a non-fluent performance in both motor and cognitive functions. In this 
study the postulated "dysmetria of thought"1733 seems to have led to a non-fluent performance that was seen most clearly in the deficits concerning the fluency tasks, but also divided attention.

Possible oculomotor deficits were not specifically assessed, instead only being ascertained by asking the patients themselves about changes in their vision. However, even if we failed to obtain specific oculomotor deficits, such an impairment could not explain the range of neuropsychological deficits which were also discernible in many oculomotorindependent tests, for example in the fluency tasks.

Finally the patients described themselves as more dejected, tired, and reduced in initiative than the controls. This result should be regarded with caution, and not as a proof of affect differences like those described by Schmahmann and Sherman. ${ }^{17}$ First of all, the group difference might simply be due to the fact that the patients were hospitalised, and at least in part worried about their diagnosis, whereas the controls were not in a comparable situation. Secondly, looking at the normative data for the POMS, all three significantly different parameters of the patient group lay within one standard deviation from the mean. The group difference could be because the controls described themselves as less dejected and tired than the norm. In summary, correlations between dejectedness and initiative, and some executive functions, cannot be completely ruled out. However, a general impact of mood did not exist.

It has been shown that the cerebellum forms part of a network of cerebro-cerebellar and cerebello-cerebral connections that mediate cognitive behaviours. ${ }^{23}$ According to the crossing of these connections the right cerebellar hemisphere should be relevant for verbal performance, while the left is critical for non-verbal performance like visual construction or visual memory. Motor impairments should be seen as ipsilateral to the lesion. The patients in our sample with either right- or left-sided lesions have been separately compared to their matched controls in order to detect whether the deficits depend on the site of the lesion. This separation showed that patients with right-sided lesions were in general more impaired than those with left-sided lesions. This difference could be, at least in part, the result of the testbattery, which had an emphasis on verbal functions. However, the patients with left-sided lesions showed no deficits in verbal functions. Instead the impaired functions were either typical "cerebral right hemisphere functions" (Visual Memory, Planning), or bilaterally organised in the frontal lobes. Surprisingly, no motor impairment was seen in either hand of the patients with left-sided lesions.

As expected, patients with right-sided lesions were impaired in the motor functioning of the hand ipsilateral to the lesion, but not in the contralateral hand. The reason for this difference in motor function between the two groups remains an open question, but the difference might explain the stronger impairment of the patients with right-sided lesions in the speed tests, because all patients performed those tests with the right hand. However, the strikingly significant impairment in verbal fluency that is only present in the patient group with right-sided lesions is in accordance with many other reports. Studies with cerebellar patients and fMRI studies have shown the relevance of the cerebellar right hemisphere for verbal fluency. ${ }^{1017} 1821$

A factor involving clinical data, such as lesion size or aetiology, that could explain the group difference between the patients with a left-sided lesion and those with a rightsided lesion has not been discernible. The fact that the right cerebellum is linked to the left cerebral hemisphere, so dominant in language and crucial for right hand movements, might explain the stronger impairment shown by the patients with right cerebellar lesions. The reported deficits of fluency, verbal working memory and abstract reasoning would also be expected after left frontal lesions. Additional difficulties in the time-based tests like TMT, and in part in Block Design, may be affected by motor impairment of the right hand. A greater general dominance of the right cerebellar hemisphere in those cognitive functions that are neuropsychologically tested has not yet been discussed in previous studies. Further research on this specific topic is needed.

Our results confirm that cognitive functions are impaired after cerebellar lesions. In accordance with the assumption of Courchesne and Allen, ${ }^{32}$ cerebellar damage did not eliminate the functions but instead impaired the performance. The deficits were most pronounced for executive functions and, probably as a consequence, effortful or strategic memory. Higher attentional processes such as working memory and divided attention were also impaired. Although, on the whole, patients with right-sided lesions were more impaired than those with left-sided lesions, the assumption that right cerebellar lesions lead to verbal deficits while left cerebellar lesions lead to spatial deficits has in part been confirmed. We interpret the greater cognitive impairment of patients with right cerebellar lesions as being due to the reciprocal anatomical and functional connections between the right cerebellum and the left cerebral hemisphere. The left cerebral hemisphere is of course dominant in language and responsible for the motor functioning of the right hand.

In general the cognitive impairment cannot be explained by motor disabilities. It seems likely that the predictive and preparative function of the cerebellum can lead to two types of dysmetria; one in motor functions and one in cognitive functions. Our findings support the idea of a dysmetria of thought resulting from cerebellar lesions. Further research is needed to determine whether the right cerebellum is comparable in dominance to the left cerebral hemisphere.

\section{Authors' affiliations}

B Gottwald, B Wilde, Z Mihajlovic, H M Mehdorn, Department of Neurosurgery, Christian Albrechts Universität, Kiel, Germany

Competing interests: none declared

\section{REFERENCES}

1 Rapoport M, van Reekum R, Mayberg H. The role of the cerebellum in cognition and behavior: a selective review. I Neuropsychiatry Clin Neurosci 2000;12:193-8.

2 Schmahmann JD, Pandya DN, The cerebrocerebellar system In: Schmahmann JD, ed. The cerebellum and cognition. International review of neurobiology, vol 41. San Diego: Academic Press, 1997:31-60.

3 Middleton FA, Strick PL. Cerebellar output channels. In: Schmahmann JD, ed. The cerebellum and cognition. International review of neurobiology, vol 41 . San Diego: Academic Press, 1997:61-83.

4 Carpenter MD. Core text of neuroanatomy, 4th edn. Baltimore: Williams \& Wilkins, 1991.

5 Allen G, Buxton RB, Wong EC, et al. Attentional activation of the cerebellum independent of motor involvement. Science 1997;275:1940-3.

6 Le TH, Pardo JV, Hu X. 4T-fMRI study of nonspatial shifting of selective attention: cerebellar and parietal contributions. J Neurophysiology 1998;79:1535-48.

7 Petersen SE, Fox PT, Posner MI, et al. Positron emission tomographic studies of the processing of single words. J Cogn Neurosci 1989;1:153-70.

8 Raichle ME, Fiez JA, Videen TO, et al. Practice-related changes in human brain functional anatomy during nonmotor learning. Cereb Cortex 1994:4:8-26.

9 Mariën $P$, Engelborghs $S$, Fabbro F, et al. The lateralized linguistic cerebellum: a review and a new hypothesis. Brain Lang 2001;79:580-600.

10 Hubrich-Ungureanu P, Kaemmerer N, Henn FA, et al. Lateralized organization of the cerebellum in a silent verbal fluency task: a functional magnetic resonance imaging study in healthy volunteers. Neurosci Lett 2002;319:91-4.

11 De Zubicaray GI, Zelaya FO, Andrew C, et al. Cerebral regions associated with verbal response initiation suppression and strategy use. Neuropsychologia 2000;38:1292-304.

12 Seger C, Desmond JE, Glover GH, et al. Functional magnetic resonance imaging evidence for right-hemisphere involvement in processing unusual semantic relationships. Neuropsychology 2000;14:361-9. 
13 Townsend J, Westerfield $M$, Leaver $E$, et al. Event-related brain response abnormalities in autism: evidence for impaired cerebello-frontal spatial attention networks. Cognit Brain Res 2001;11:127-45.

14 Berquin PC, Giedd JN, Jacobsen LK, et al. Cerebellum in attention-deficit hyperactivity disorder. Neurology 1998;50:1087-93.

15 Mostofski SH, Reiss AL, Lockhart P, et al. Evaluation of cerebellar size in attention-deficit hyperactivity disorder. J Child Neurol 1998;13:434-9.

16 Castellanos FX, Giedd JN, Berquin PC, et al. Quantitative brain magnetic resonance imaging in girls with attention-deficit/hyperactivity disorder. Arch Gen Psychiatry 2001;58:289-95.

17 Schmahmann JD, Sherman JC. The cerebellar cognitive affective syndrome. Brain 1998;121:561-79

18 Riva D, Giorgi C. The cerebellum contributes to higher functions during development: evidence from a series of children surgically treated for posterio fossa tumours. Brain 2000;123:1051-61.

19 Levisohn L, Cronin-Golomb A, Schmahmann JD. Neuropsychological consequences of cerebellar tumour resection in children. Brain 2000; 123:1041-50

20 Molinari M, Leggio MG Silveri MC. Verbal fluency and agrammatism. In: Schmahmann JD, ed. The cerebellum and cognition. International review of neurobiology, vol 41. San Diego: Academic Press, 1997:325-39.

21 Leggio MG, Silveri MC, Petrosini L, et al. Phonological grouping is specifically affected in cerebellar patients: a verbal fluency study. I Neurol Neurosurg Psychiatry 2000;69:102-6.

22 Fiez JA, Petersen SE, Cheney MK, et al. Impaired non-motor learning and error detection associated with cerebellar damage. Brain 1992;115:155-78.

23 Grafman J, Litvan I, Massaquoi S, et al. Cognitive planning deficit in patients with cerebellar atrophy. Neurology 1992;42:1493-6.

24 Appollonio IM, Grafman J, Schwartz V, et al. Memory in patients with cerebellar degeneration. Neurology 1993;43:1536-44.

25 Drepper J, Timmann D, Kolb FP, et al. Non-motor associative learning in patients with isolated degenerative cerebellar disease. Brain 1999; 122:87-97.

26 Townsend J, Courchesne E, Covington J, et al. Spatial attention deficits in patients with acquired or developmental cerebellar abnormality. J Neurosci 1999; 19:5632-43.

27 Courchesne E, Townsend J, Akshoomoff NA, et al. Impairment in shiffing attention in autistic and cerebellar patients. Behav Neurosci 1994; 108:848-65.

28 Helmuth LL, Ivry RB, Shimizu N. Preserved performance by cerebellar patients on tests of word generation, discrimination learning and attention. Learn Mem 1997:3:456-74.

29 Beldarrain MG, Garcia-Moncó JC, Quintana JM, et al. Diaschisis and neuropsychological performance after cerebellar stroke. Eur Neurol 1997;37:82-9

30 Daum I, Ackermann H. Neuropsychological abnormalities in cerebellar syndromes - fact or fiction? In: Schmahmann JD, ed. The cerebellum and cognition. International review of neurobiology, vol 41. San Diego: Academic Press, 1997:61-83.

31 Ravizza SM, Ivry RB. Comparison of the basal ganglia and cerebellum in shifting attention. J Cogn Neurosci 2001;13:285-97.
32 Courchesne E, Allen G. Prediction and preparation, fundamental functions of the cerebellum. Learn Mem 1997;4:1-35.

33 Schmahmann JD. The cerebellar cognitive affective syndrome: clinical correlations of the dysmetria of thought hypothesis. Int Rev Psychiatry 2001:13:313-22.

34 Moschner C, Crawford TJ, Heide W, et al. Deficits of smooth pursuit initiation in patients with degenerative cerebellar lesions. Brain 1999;122:2147-58.

35 Lehrl S. Mehrfachwahl Wortschatztest MWT-B. Erlangen: Perimed Verlag, 1975.

36 Wechsler D. Wechsler Memory Scale-Revised manual. San Antonio: Psychological Corporation, 1987.

37 Härtling C, Markowitsch HJ, Neufeld H, et al. WMS-R Wechsler Gedächtnistest-Revidierte Fassung. Bern: Hans Huber Verlag, 2000.

38 Lezak MD. Neuropsychological Assessment, 3rd edn. New York: Oxford University Press, 1995

39 Lee GP, Loring DW, Newell J, et al. Figural fluency on the Five-Point Test: preliminary normative and validity data. Int Neuropsychol Soc Program Abstracts 1994;1:51.

40 Spreen O, Strauss E. A compendium of neuropsychological tests, administration, norms and commentary. New York: Oxford University Press, 1998.

41 Kaufman AS, Kaufman NL. K-ABC Kaufman Assessment Battery for Children. Circle Pines, MN: American Guidance Service, 1983

42 Melchers P, Preuss U. K-ABC Kaufman-Assessment Battery for Children, Interpretationshandbuch, 2. Auflage. Amsterdam: Swets \& Zeitlinger, 1994

43 Luria AR. Higher cortical functions in man, 2nd edn. New York: Basic Books, 1980.

44 Nelson HE. A modified card sorting test sensitive to frontal lobe defects. Cortex 1976;12:313-24.

45 Stroop JR. Studies of interference in serial verbal reactions. J Exp Psychol 1935; 18:643-62.

46 Bäumler G. Farbe-Wort-Interferenztest (FWIT) nach J.R. Stroop. Göttingen: Verlag für Psychologie, Hogrefe, 1985.

47 Wechsler D. WAIS-R Manual. New York: Psychological Corporation, 1981

48 Tewes U, ed. HAWIE-R Hamburg-Wechsler Intelligenztest für Erwachsene Revision. Bern: Hans Huber Verlag, 1991.

49 Rey A. Psychological examination of traumatic encephalopathy. Arch Psychol 1941;28:286-340.

50 Zimmermann P, Fimm B. Testbatterie zur Aufmerksamkeitsprüfung. Würselen: PSYTEST, 1993.

51 Partington JE, Leiter RG. Partington's Pathway Test. Psychological Service Center Bull 1949;1:9-20.

52 Tiffin J. Purdue Pegboard: examiner manual. Chicago: Science Research Associates, 1968.

53 Mc Nair DM, Lorr M, Droppleman LF, et al. POMS Profile of Mood StatesDeutsche Bearbeitung von Biehl, Dangel \& Reiser. Weinheim: Beltz, 1981.

54 Daum I, Ackermann H, Schugens MM, et al. The cerebellum and cognitive functions in humans. Behav Neurosci 1993;107:411-19.

55 Gottwald B, Mihajlovic Z, Wilde B, et al. Does the cerebellum contribute to specific aspects of attention? Neuropsychologia 2003;41:1452-60. 